International Journal of Medical Anesthesiology 2021; 4(1): 122-126

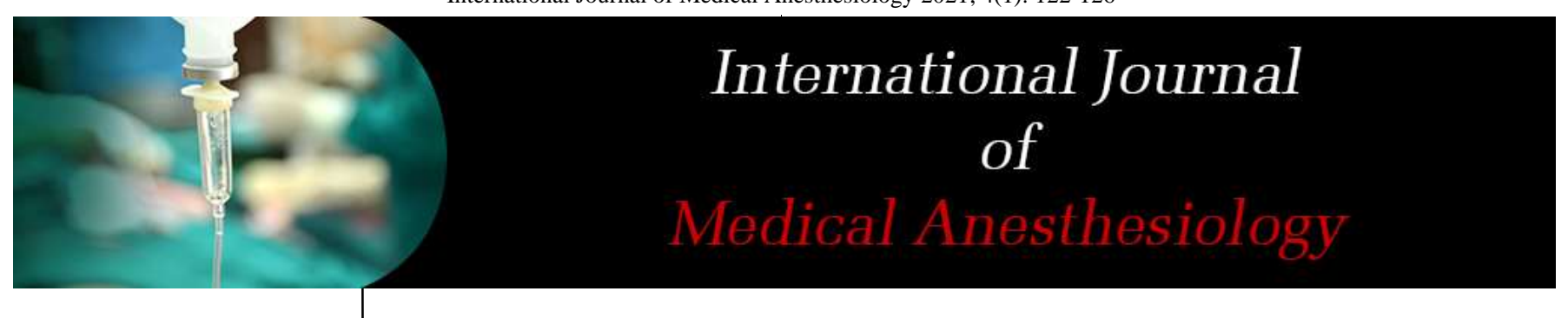

E-ISSN: 2664-3774

P-ISSN: 2664-3766 www.anesthesiologypaper.com IJMA 2021; 4(1): 122-126

Received: $20-11-2020$

Accepted: 28-12-2020

Dr. Mrunalini Patel

Assistant Professor, B.J.

Medical College, Ahmedabad,

Gujarat, India

Dr. Daxa Hiren Oza

Assistant Professor, GMERS

Medical College Gandhi Nagar,

Gujarat, India

Dr. Krati Singhal

B.J. Medical College,

Ahmedabad, Gujarat, India

Dr. Aishwariya T Kulkarni First Year Resident,

Department of Anaesthesia B.J. Medical College,

Ahmedabad, Gujarat, India

Corresponding Author: Dr. Mrunalini Patel Assistant Professor, B.J. Medical College, Ahmedabad, Gujarat, India

\section{Comparison of dexmedetomidine vs labetalol for attenuation of haemodynamic stress responses to laryngoscopy and endotracheal intubation}

\author{
Dr. Mrunalini Patel, Dr. Daxa Hiren Oza, Dr. Krati Singhal and Dr. \\ Aishwariya T Kulkarni
}

DOI: $\underline{\text { https://doi.org/10.33545/26643766.2021.v4.i1b.209 }}$

\begin{abstract}
Background: We hypothesized that the effectiveness of dexmedetomidine versus labetalol in attenuation of hemodynamic stress responses of laryngoscopy and intubation and effect of dexmedetomidine in post-operative sedation. Also we studied adverse effect of both the drugs.

Method: Following approval by institutional ethics committee and 60 patients, who posted for elective surgeries under general anaesthesia taken. Study drug was given in $100 \mathrm{ml}$ of saline over $10 \mathrm{mins}$. Inj dexmedetomine 1 microgram/ $\mathrm{kg}$ and Inj. labetalol $0.25 \mathrm{mg} / \mathrm{kg}$ given and parameters like HR, SBP, DBP, Spo2, and sedation score were monitored immediately and after 3,5 and 10 minutes.

Result: There was a reduction in the heart rate and mean arterial pressure response to intubation in both Dexmedetomidine and labetalol but there was statistically significant reduction of heart rate and arterial pressure response to intubation in Dexmedetomidine group. There was statistically significant sedation in Dexmedetomidine group.

Conclusion: Dexmedetomidine $1 \mu / \mathrm{Kg}$ given slowly over 10 minutes intravenously 5 minutes prior to induction, attenuates the cardiovascular responses to laryngoscopy and intubation in a better manner than Labetalol $0.25 \mathrm{mg} / \mathrm{Kg}$.
\end{abstract}

Keywords: Dexmedetomidine, labetalol, stress response, laryngoscopy and intubation

\section{Introduction}

Laryngoscopy and endotracheal intubation has become one of the frequently performed procedures in the practice of anaesthesia. The circulatory response to laryngeal and tracheal stimulation following laryngoscopy and intubation was first documented by Reid and Brace [1] in 1940 and by King et al. ${ }^{[2]}$ in 1951. These cardiovascular response is a reflex phenomenon, mediated by vagus (X) \& Glossopharyngeal (IX) cranial nerves. Vagus \& Glossopharyngeal nerves carry the afferent stimulus from epiglottis \& infra glottic region \& activate the vasomotor centre to cause a peripheral sympathetic adrenal response to release adrenaline \& noradrenaline ${ }^{[3]}$. There are variuos types of pretreatments for topical anaesthesia of larynx to administration of several classes of drugs like nitroglycerine, B blockers and opioids have been made. Every technique has its own advanges and disadvantages. Use of multi modal therapy has been in practice to attenuate this response. The increase in Pulse rate, Blood pressure are usually transitory ( peak effect within 1- 2 minutes after intubation which usually normalized within five minutes post intubation) [4] 'Normal, healthy persons tolerate this response, but in susceptible individuals such as those with hypertension, coronary artery disease, cerebrovascular disease, and intracranial aneurysm this transient sympathetic response can evoke life threatening conditions like arrhythmias, myocardial infraction, left ventricle failure and rupture of aneurys ${ }^{[5]}$. Different types of pharmacological \& non - pharmacological methods have been used to attenuate the haemodynamic response to laryngoscopy \& endotracheal intubation. Dexmedetomidine is a selective alpha 2 agonist that provides multimodal features like sedation, hypnosis, analgesia and sympatholisis, it also decreases level of catecholamines during surgery and maintains intraoperative hemodynamics. Perioperative infusion of dexmedetomidine is effective in attenuating sympathoadrenal response to tracheal intubation. It has significant anaesthetic and opioid sparing effect ${ }^{[7]}$. Labetalol is an oral and parenteral antihypertensive adrenergic antagonist that has an. effect on both selective $\alpha 1$ and nonselective $\beta 1$ and $\beta 2$. 
It has a rapid onset of action, it reaches its peak effect at 5$15 \mathrm{~min}$ after i.v. injection, it rapidly redistributes (5.9-min redistribution half-life) ${ }^{[8]}$, and it lowers BP by decreasing systemic vascular resistance ( $\alpha 1$-blockade), whereas reflex tachycardia is attenuated by simultaneous $\beta$-blockade.

\section{Materials and Methods}

This randomised prospective, case control study was conducted after written informed consent of patients and relative, fulfilling inclusion criteria. Following approval by institutional ethics committee and 60 patients who were posted for elective surgeries under general anaesthesia were included in study. Inclusion Criteria are Patients of age between 18-60 years, ASA 1 and 2, Scheduled for elective surgeries to be undertaken in general anaesthesia. Exclusion Criteria includes patient refusal, patients with H/o cardiac, respiratory, renal or hepatic dysfunction or failure, pregnant females, coagulation disorders, allergy to study medications, patients on adrenoreceptors agonists or antagonists, patients with difficult intubation and those patients in whom intubation was attempted for more than 30 second.

All patients were examined thoroughly pre-operatively and history was taken in detailed regarding previous drug therapy, drug sensitivity, any surgical intervention carried out, anaesthesia and any complication if occurred. All necessary investigation were advised. All patients were randomly divided in two groups about which patients were not aware. The drug administrator and who record parameter was same person.

Patient was taken on OT table and after securing iv line baseline parameters were recorded. These parameters were heart rate (HR), systolic blood pressure (SBP), diastolic blood pressure (DBP), oxygen saturation (spo2), sedation score. Patients were pre medicated with inj glycopyrrolate 4 microgram/ kg, fentanyl 1 microgram/ kg, and ondanestron $0.15 \mathrm{mg} / \mathrm{kg}$ iv. According to group study drug was given in $100 \mathrm{ml}$ of saline over 10 mins. Group D, inj. dexmedetomine 1 microgram/ $\mathrm{kg}$ and group L, inj labetalol $0.25 \mathrm{mg} / \mathrm{kg}$ given. After injection of study drug parameters like HR, SBP, DBP, Spo2, and sedation score were monitored immediately and after 3 and 5 minutes. All patients were pre oxygenated for 5 minutes with $100 \%$ oxygen. Any hypotension if occurred (SBP $<20 \%$ of baseline) or bradycardia (HR $<50$ beats per minute) was treated with injection Mephentermine $6 \mathrm{mg}$ and injection Atropin $0.6 \mathrm{mg}$ respectively. After 10 minutes of giving study drug conventional GA was given to all patients with injection thiopentone sodium $(4-7 \mathrm{mg} / \mathrm{kg}$ ) till loss of eyelash reflex followed by injection suxamethonium $2 \mathrm{mg} / \mathrm{kg}$. ventilation of lungs was assisted till disappearance of facciculation. Laryngoscopy was performed by resident doctor for tracheal intubation. HR,SBP,DBP,MAP,Spo2 were recored during surgery 2,5,10 minutes after intubation During surgery anaesthesia was maintained with sevoflurane/Desflurane inhalation anaesthesia in oxygen with injection vecuronium/atracurium as muscle relaxant. Intraoperatively hemodynamic parameters were recorded every 15 minutes till extubation. Complication were recorded. After completion of surgery neuromuscular block was reversed by injection neostigmine 50 microgram $/ \mathrm{kg}$ and injection glycopyrrolate $8 \mathrm{microgram} / \mathrm{kg}$. After complete recovery patient was shifted to PACU and monitored. Sedation score was accessed post operatively till 8 hours. Analysis was done using SPSS version 20 (IBM SPSS
Statistics Inc., Chicago, Illinois, USA) Windows software program. The variables were assessed for normality using the Kolmogorov

Smirnov test. Descriptive statistics included computation of percentages, means and standard deviations. Both Paired and un-paired t-test (student t-test) were used for quantitative data comparison. Chi-square test used for the analysis of qualitative data. Level of significance was set at $\mathrm{p} \leq 0.05$.

\section{Results and Discussion}

The study was done in 60 patients belonging to ASA class I and II undergoing elective surgeries under general anaesthesia. The groups were matched for demographic data, and there was no statistically significant difference found between the groups in age and sex (table 1,2). Baseline parameters are comparable between groups (table 3 ). There is no statistically significant difference between the groups. Heart rate decreased after injection of the drug in $\mathrm{D}$ and $\mathrm{L}$ group. The fall in heart rate was more in group $\mathrm{D}$ than in group L. SBP after injection of drug and after induction were comparable between the groups. There is no statistically significant difference $(\mathrm{p}>0.005)$. After laryngoscopy and intubation, SBP decreased in group D and $\mathrm{L} \quad(p<0.05)$. In group $\mathrm{D}$ the presures responce after intubation at 2, 5, 10 minutes interval were less than group L. DBP after injection of drug and after induction were comparable between the groups. There is no statistically significant difference $(\mathrm{p}>0.005)$. After laryngoscopy and intubation DBP decreased in group D and L $(p<0.05)$. In group $\mathrm{D}$ the presures response after intubation at $2,5,10$ minutes interval were less than group L. There is no significant difference in SPO2 in both the groups. There was statistically significant difference in sedation score of dexmedetomidine group. But the average sedation score was 2 that is all patients were calm and tranquil in Group D. Direct Laryngoscopy and tracheal intubation during general anaesthesia leads to sympathetic stimulation and release of plasma catecholamines which manifests clinically as tachycardia, hypertension along with raised intraocular and intracerebral pressure ${ }^{[13]}$. Hemodynamic and hormonal responses to tracheal intubation can be profound and associated with serious cardiovascular and cerebral side effects ${ }^{[14]}$. Normally these hemodynamic responses are transient having its peak effect within 1-2 minutes after intubation and is normalized within five minutes post intubation 4.

The response may be unpredictable in duration as it also depends upon comorbid condition of the patients. Sometimes the abrupt increase in systolic blood pressure may lead to untoward effects in patients of cardiovascular and cerebrovascular diseases ${ }^{[15]}$. An increase in heart rate, together with elevation of systolic blood pressure increases the rate pressure product, thus compromising myocardial contractility and oxygen supply. In our study we compared Dexmedetomidine $1 \mu / \mathrm{kg}$ and labetalol $0.25 \mathrm{mg} / \mathrm{kg}$. Both the drugs produce peak effect after 5 minutes. We had induced all the patients 5 minutes after test drug. In our study dexmeditomidine is given over $10 \mathrm{~min}$ with continuous monitoring of heart rate, none of the patients developed bradycardia that required atropine.(figure 1) Bradycardia after dexmeditomidine was reported in some studies with the bolus injection. Scheinin et al reported that the use of $\alpha 2$ agonist leads to bradycardia ${ }^{[10]}$. 
In our study in group D, the mean baseline SBP was 119.8 \pm 8.45 . At no point of time during the post intubation period did the mean SBP rise above the baseline mean SBP value of the study population in this group. (table 4, fig- 2) In the study by Menda F et al. ${ }^{[12]}$, they found that the SBP values were below the baseline values in the Dexmedetomidine group at all measurement times, which was in accordance with our results.

Our study results also concurred with the results of Keniya VM et al. ${ }^{[7]}$ and Yildiz M et al. ${ }^{[11]}$ who observed that although not completely abolished, Dexmedetomidine administered at a dose of $1 \mu \mathrm{g} / \mathrm{kg}$ IV was able to suppress the SBP response to laryngoscopy and intubation. Dexmeditomidine over $10 \mathrm{~min}$ with continuous monitoring of arterial oxygen saturation with pulse oxymeter showed no desaturation (spo2-<95\%) in any patient. Ebert et al. didn't observe any apnea, airway obstruction and hypoxemia with bolus doses of dexmedetomidine in their study and they reported that depression of respiration may be seen due to deep sedation. In another study in which the infusion of opioid and $\alpha 2$ adrenergic agonists were compared, it was concluded that dexmedetomidine doesn't cause significant respiratary depression and it decreases the risk of apnea. Hofer et al. reported that dexmedetomidine seems to be a good choice in the critical patients in whom ventilation can be depressed with narcotics ${ }^{[17,18]}$. Labetalol in a dose of $0.25 \mathrm{mg} / \mathrm{kg}$ had reduced the heart rate. But the reduction was modest compared to dexmeditomidine (table-4) the reduction in arterial pressure after labetalol was mild (table5) that was statistically insignificant. Dexmeditomidine preinjection effectively attenuated the hemodynamic response to intubation compared to labetalol. (Table-4, 5, 6). In our study there was statistically significant difference in sedation score of dexmedetomidine group and it was maximum 3.0+ .01 (table 10) after 5 minutes of administrating the drug.similar results were seen in study by carollo DS et al. ${ }^{[18]}$ and keating GM et al. ${ }^{[19]}$ and 2 hours Post extubation sedation score was $2.63+0.49$. Which is statistically significant. All patients were sedated but arrousable and calm. as stated by study conducted Constantin J-M et al. ${ }^{[20]}$, the use of dexmedetomidine has resulted in shorter time of extubation as well as reduced incidence of agitated delirium post operatively stated by
Reade MC et al. ${ }^{[21]}$ Extubation is equally important as it can be detrimental for high risk patients. Dexmedetomidine as well as labetalol enabled a smooth change over during reversal till post-extubation phase. Due to analgesic and sympatholytic property, dexemedotomidine had led to stable haemodynamics with good control of heart rate and blood pressure when compared to labetalol at the time of extubation as well as postoperatively.

Table 1: Distribution of gender in both the groups

\begin{tabular}{|c|c|c|c|}
\hline \multirow{2}{*}{ GENDER } & \multicolumn{2}{|c|}{ GROUPS } & \multirow{2}{*}{ Total } \\
\hline & D & L & \\
\hline \multirow{2}{*}{ Female } & 10 & 14 & 24 \\
\hline & $33.3 \%$ & $46.7 \%$ & $40.0 \%$ \\
\hline \multirow[t]{2}{*}{ Male } & 20 & 16 & 36 \\
\hline & $66.7 \%$ & $53.3 \%$ & $60.0 \%$ \\
\hline \multirow{2}{*}{ Total } & 30 & 30 & 60 \\
\hline & $100.0 \%$ & $100.0 \%$ & $100.0 \%$ \\
\hline$p$-value & \multicolumn{3}{|c|}{0.292 (NS) } \\
\hline
\end{tabular}

Table 2: Distribution of age in both the groups

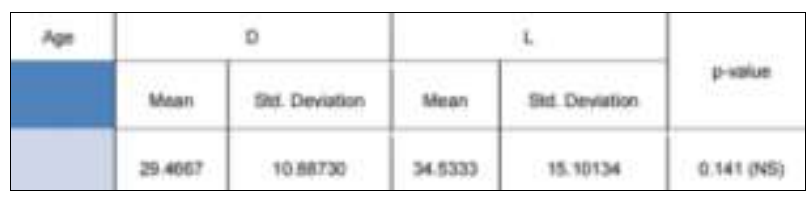

Table 3: Base Line Parameters

\begin{tabular}{|c|c|c|c|c|c|}
\hline \multirow{2}{*}{ At 0 Minute } & \multicolumn{2}{|c|}{ Group D } & \multicolumn{2}{|c|}{ Group L. } & \multirow[b]{2}{*}{ pualue } \\
\hline & Mkan & $\begin{array}{c}\text { SNd. } \\
\text { Deviation }\end{array}$ & Mean & $\begin{array}{c}\text { Sid } \\
\text { Deviation }\end{array}$ & \\
\hline Heart rate & 85.1333 & 8.95095 & $8 \times .1000$ & $10.4563 t$ & 0.243 (NS) \\
\hline SBP & 119.8000 & 143392 & 122.9000 & 10.11775 & 0202 (NS) \\
\hline DEP & 80.2667 & 486319 & 81.2333 & 6.70915 & 0013 (NS) \\
\hline $\mathrm{SpO2}$ & 990333 & 66868 & $\$ 90000$ & 52523 & 0.831 (NS) \\
\hline Ss & 6000 & $00000^{\prime \prime}$ & 0000 & $00000^{\circ}$ & \\
\hline
\end{tabular}

Table 4: Intergroup comparison of SBP

\begin{tabular}{|c|c|c|c|c|c|}
\hline \multirow{2}{*}{ SBP } & \multicolumn{2}{|c|}{ Group D } & \multicolumn{2}{|c|}{ Group L } & \multirow{2}{*}{ p-value } \\
\hline & Mean & Std. Deviation & Mean & Std. Deviation & \\
\hline At 0 Minute & 119.8000 & 8.43392 & 122.9000 & 10.11775 & 0.202 (NS) \\
\hline $\begin{array}{c}\text { Immediately After } \\
\text { Administration of drug }\end{array}$ & 118.8000 & 8.54764 & 114.7667 & 7.36105 & 0.250 (NS) \\
\hline At 3 Minutes & 116.2333 & 7.85069 & 112.9667 & 6.86562 & 0.092 (NS) \\
\hline At 5 Minutes & 108.1000 & 6.20539 & 109.4667 & 6.15172 & 0.395 (NS) \\
\hline Immediately After Intubation & 118.9333 & 7.38560 & 131.1000 & 9.20401 & 0.001 (Sig.) \\
\hline 2 minutes After Intubation & 116.9333 & 7.70550 & 127.6667 & 8.54333 & 0.001 (Sig.) \\
\hline 5 minutes After Intubation & 114.5000 & 7.85098 & 124.9667 & 8.19791 & 0.001 (Sig.) \\
\hline 10 minutes After Intubation & 111.9333 & 7.71444 & 121.9333 & 7.59734 & 0.001 (Sig.) \\
\hline
\end{tabular}


Table 5: Intergroup comparision of DBP

\begin{tabular}{|c|c|c|c|c|c||}
\hline \multirow{2}{*}{ DBP } & \multicolumn{2}{|c|}{ Group D } & \multicolumn{2}{c||}{ Group L } & \multirow{2}{*}{ p-value } \\
\cline { 2 - 5 } At 0 Minute & $\begin{array}{c}\text { Mean } \\
80.2667\end{array}$ & $\begin{array}{c}\text { Std. Deviation } \\
4.86319\end{array}$ & $\begin{array}{c}\text { Mean } \\
81.2333\end{array}$ & $\begin{array}{c}\text { Std. Deviation } \\
6.70915\end{array}$ & 0.013 (NS) \\
\hline $\begin{array}{c}\text { Immediately After } \\
\text { Administration of drug }\end{array}$ & 74.1000 & 5.10139 & 76.6667 & 6.32637 & 0.089 (NS) \\
\hline At 3 Minutes & 72.8667 & 4.79751 & 75.7000 & 5.87308 & 0.045 (Sig.) \\
\hline At 5 Minutes & 72.5333 & 4.45462 & 74.2667 & 5.85417 & 0.202 (NS) \\
\hline Immediately After Intubation & 79.8000 & 5.56095 & 88.0667 & 5.81872 & 0.001 (Sig.) \\
2 minutes After Intubation & 74.4000 & 5.62997 & 86.5667 & 6.09513 & 0.001 (Sig.) \\
\hline 5 minutes After Intubation & 74.9333 & 4.20946 & 84.2000 & 5.96773 & 0.001 (Sig.) \\
\hline 10 minutes After Intubation & 73.7333 & 3.46344 & 80.8000 & 4.45978 & 0.001 (Sig.) \\
\hline
\end{tabular}

Table 6: Intergroup comparison of SPO2

\begin{tabular}{|c|c|c|c|c|c|}
\hline \multirow{2}{*}{ SpO2 } & \multicolumn{2}{|c|}{ Group D } & \multicolumn{2}{c|}{ Group L } & \multirow{2}{*}{ p-value } \\
\cline { 2 - 5 } At 0 Minute & Mean & Std. Deviation & Mean & Std. Deviation & \multirow{2}{*}{0.831 (NS) } \\
\hline $\begin{array}{c}\text { Immediately After } \\
\text { Administration of drug }\end{array}$ & 99.0333 & .66868 & 99.0000 & .52523 & 0.8000 \\
\hline At 3 Minutes & 99.1333 & .81931 & 99.0000 & .74278 & 0.512 (NS) \\
\hline At 5 Minutes & 98.8667 & 1.07425 & 98.6667 & 1.02833 & 0.464 (NS) \\
\hline Immediately After Intubation & 99.8667 & .34575 & 99.9000 & .30513 & 0.694 (NS) \\
\hline 2 minutes After Intubation & 99.7667 & .43018 & 99.9000 & .30513 & 0.171 (NS) \\
\hline 5 minutes After Intubation & 99.8667 & .34575 & 99.9000 & .30513 & 0.694 (NS) \\
\hline 10 minutes After Intubation & 99.9000 & .30513 & 99.8667 & .34575 & 0.694 (NS) \\
\hline
\end{tabular}

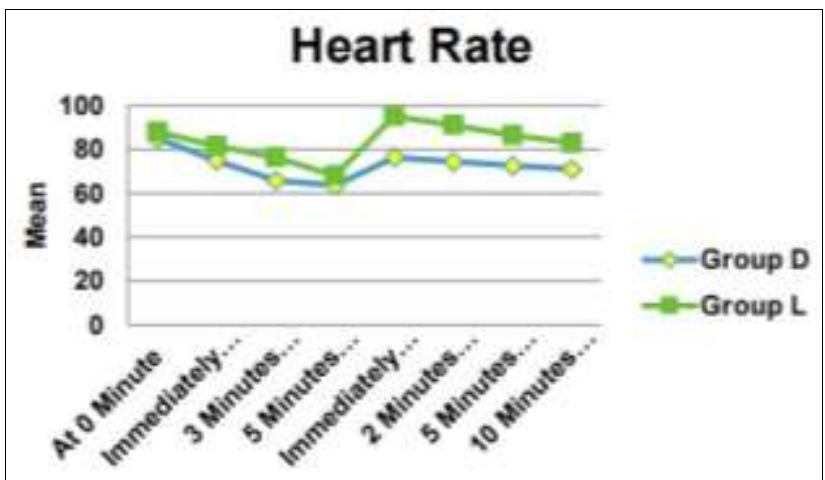

Fig 1: Intergroup comparison of Heart rate

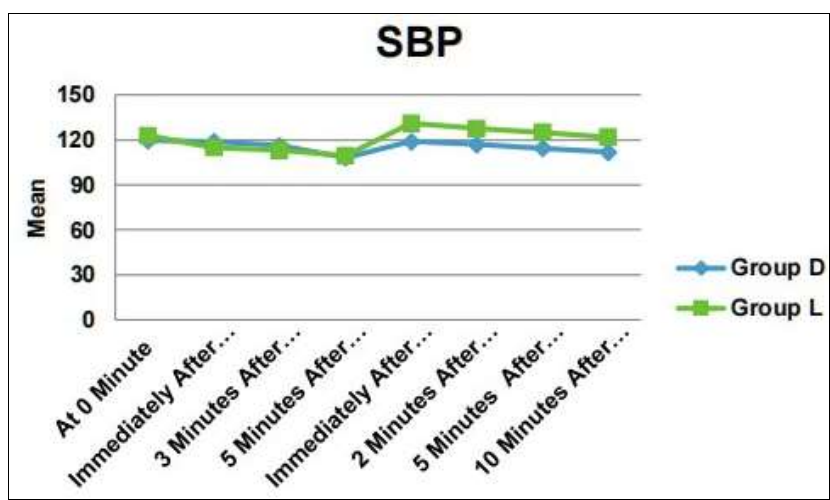

Fig 2: Intergroup comparison of SBP

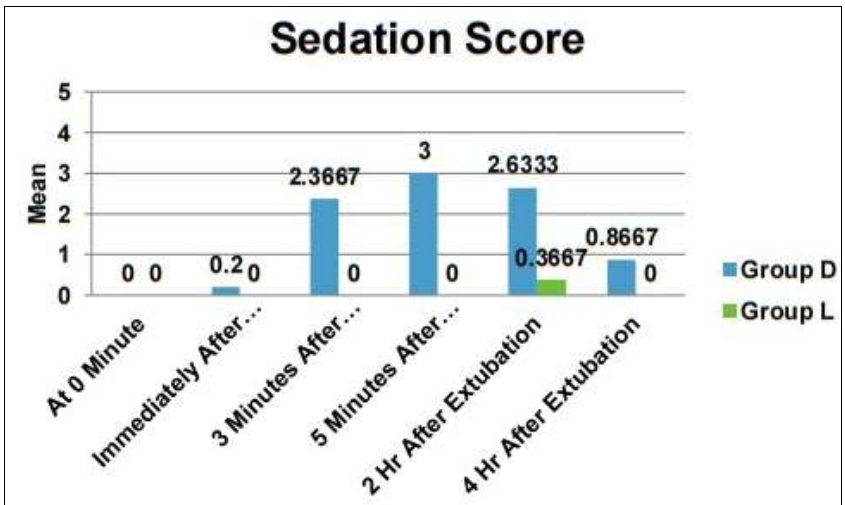

Fig 3: Intragroup Comparison of Post-Operative Sedation in D Group

\section{Conclusion}

The results of this study demonstrated that dexmedetomidine is an effective agent for blunting the hemodynamic response to laryngoscopy and tracheal intubation. There was significant decreased in hemodynamic parameter like HR, SBP, DBP and MAP from baseline after laryngoscopy and tracheal intubation in dexmedetomidine group as compared to labetalol. The difference was statistically significant and without any side effect. We conclude that, Dexmedetomidine $1 \mu / \mathrm{Kg}$ given slowly over 10 minutes intravenously 5 minutes prior to induction, 
attenuates the cardiovascular responses to laryngoscopy and intubation in a better manner than Labetalol $0.25 \mathrm{mg} / \mathrm{Kg}$.

\section{References}

1. Reid, Brace: Irritation of respiratory tract and its reflex effect on heart Surgery; Gynaecology Obstetrics 1940;70:157.

2. King BD, Harris LC, Greitenstein FE, Elder JD, Dripps RD. Reflex circulatory response to direct laryngoscopy and tracheal intubation Performed during general anaesthesia - Anaesthesiology 1951;12:56-62.

3. Derbyshire DR, Chmielewski A, Fell D, Vaters M, Achola K, Smith G. Plasma catecholamine response to tracheal intubation. Br J Anaesth 1983;55:855-9.

4. Raval DL, Yadav VP. A comparative study of two different doses of dexmedetomdine on haemodyamic responses to induction of anaesthesia and tracheal intubation. Journal of Clinical and Experimental Research 2014;2(3):163-168.

5. Fox EJ, Sklar GS, Hill CH, Villanue Var, King BD. Complications related to the pressor response to endotracheal intubation. Anaesthesiology 1977;47:5245.

6. Textbook of pharmacology \& physiology in anesthetic practice- Robert K Stoelting-4 th edition 340-45.

7. Keniya VM, Ladi S, Naphade R. Dexmedetomidine attenuates sympathoadrenal response to tracheal intubation and reduces perioperative anaesthetic requirement. Indian J Anaesth 2011;55:352-7.

8. Kanto J, Allonen H, Kleimola T. Pharmacokinetics of labetalol in healthy volunteers. Int J Clin Pharmacol Ther Toxicol 1981;19:41-44.

9. Miller RD, Eriksson LI, Fleisher LA, Wiener-Kronish JP, Young WL. Miller's Anesthesia. Philadelphia, Churchill Livingstone, 7th edition.

10. Scheinin B, Lingren L, Randell T, Scheinin H, Scheinin M. Dexmedetomidine attenuates sympathoadrenal responses to tracheal intubation and reduces the need for thiopentone \& preoperative fentanyl. BJA. 1992; 68:126-131.

11. Yildiz M, Tavlan A, Tuncer S, Reisli R et al. Effect of dexmedetomidine on hemodynamic responses to laryngoscopy \& intubation. BJA 2006;7:43-52.

12. Menda $\mathrm{F}$ et al. Dexmedetomidine as an adjunct to anesthetic induction to attenuate the hemodynamic response to endotracheal intubation in patients undergoing fast track CABG. Annuals of Cardiac Anesthesia 2010;13:16-21.

13. Bajwa SS, Kaur J, Singh A, Parmar SS, Singh G, Kulshrestha A et al. Attenuation of pressor response and dose sparing of opioids and anaesthetics with pre

14. Operative dexmedetomidine. Indian $\mathbf{J}$ Anaesth 2012;56:123-8.

15. Pernerstorfer T, Krafft P, Fitzgerald RD, Krenn CG, Chiari A, Wagner O et al. Stress response to tracheal intubation: direct laryngoscopy compared with blind oral intubation. Anaesthesia [Internet] 1995;50(1):1722. Available from: http://www.ncbi.nlm.nih.gov/pubmed/7702137

16. Singh SP, Quadir A, Malhotra P. Comparison of esmolol and labetalol, in low doses, for attenuation of sympathomimetic response to laryngoscopy and intubation. Saudi J Anaesth 2010;4(3):163-168.

17. Kewalramani Alka et al. Comparison of labetalol versus dexmedetomidine to assess the haemodynamic responses to laryngoscopy and intubation during induction of general anaesthesia - a prospective, randomized, controlled study. Indian Journal of Clinical Anaesthesia 2016;3(4):512-517.

18. EP MacCarthy, SS Bloomfield. Labetalol: A Review of Its Pharmacology, Pharmacokinetics, Clinical Uses and Adverse Effects. The Journal of Human Pharmacology and Drug Therapy 1983;3:1.

19. Carollo DS, Nossaman BD, Ramadhyani U. Dexmedetomidine: a review of clinical applications. Curr Opin Anaesthesiol 2008;21:457-461.

20. Keating GM. Dexmedetomidine: a review of its use for sedation in the intensive care setting. Drugs 2015;75:1119-1130.

21. Constantin J-M, Momon A, Mantz J et al. Efficacy and safety of sedation with dexmedetomidine in critical care patients: a meta-analysis of randomized controlled trials. Anaesth Crit Care Pain Med 2016;35:7-15.

22. Reade MC, Eastwood GM, Bellomo R et al. Effect of dexmedetomidine added to standard care on ventilatorfree time in patients with agitated delirium: a randomized clinical trial. JAMA 2016;315:1460-1468. 